\title{
As doutrinas jurídicas de hoje e a lição de Santi romano: o direito internacional*
}

\author{
Piero Ziccardi**
}

\begin{abstract}
Resumo: O artigo apresenta as linhas mestras do pensamento do jurista italiano Santi Romano sobre o direito internacional e o impacto do mesmo na cultura jurídica européia. Em particular, analisa os pressupostos da teoria do ordenamento jurídico internacional desenvolvida por Romano e seus discípulos na Itália do segundo pós-guerra.

Palavras-chave: Santi Romano; ordenamento jurídico internacional; institucionalismo; Comunidade internacional.
\end{abstract}

\begin{abstract}
This article presents the guidelines of the thought of the Italian lawyer Santi Romano on the international law, and its impact on the European legal culture. In particular, it analyses the assumptions of the theory of the legal system of international law developed by Romano and his disciples during the second Pos-war in Italy.

Keywords: Santi Romano. International legal system. Institutionalism. International Community.
\end{abstract}

Certamente não deixaria de participar como atento ouvinte do congresso promovido pelo ISAP, levando em conta a excepcional importância que a obra de Santi Romano teve para o direito internacional e sendo bem consciente do débito que muitos de nós, da escola italiana, temos em relação a ele. Tinha sido designado palestrante, em uma escolha muito feliz, Giorgio Balladore Pallieri, em cujas lições o pensamento de Santi Romano encontra-se presente sob dois aspectos, ambos importantes mesmo se contrapostos: por um lado, como apoio a uma ampla análise crítica em relação à doutrina que se tornou dominante no âmbito do movimento positivista, inspirada na concepção estatalista do direito; mas por outro lado, como objeto de uma ulterior reflexão voltada a superar a contraposição entre institucionismo e normativismo com a finalidade de resgatar a construção sistêmica nos esquemas do normativismo, e isso graças a um enriquecimento deles, aproveitado das lições de Romano - mesmo não sendo somente deles -, e que conduz a individuar o ordenamento através da sua constituição, entendida como expressão em termos normativos de uma determinada ordem social.

\footnotetext{
* Le dottrine giuridiche di oggi e l'insegnamento di Santi Romano: Il Diritto Internazionale, traduzido da língua italiana por Arno Dal Ri Júnior.

** Professor Emérito de Direito Internacional na Università deli studi di Milano, Itália. Ėmerit de l'Institut de Droit International.
} 
Deve-se lamentar que circunstâncias desafortunadas, felizmente depois superadas, nos tenham privado da palestra de Baliadore Pallieri, que resta insubstituível, até mesmo porque teria tido o valor de um testemunho direto sobre o modo através do qual o pensamento de Santi Romano desenvolveu sua influência sobre a escola italiana de direito internacional, sobre a combinação de tal influência com aquelas provenientes das outras escolas, sejam as italianas da época de Dionisio Anzilotti e de Tomaso Perassi, como também de Donato Donati, por um lado, sejam, por outro lado, as estrangeiras, sobretudo as de Hans Kelsen e de Alfred Verdross.

A minha palestra não deve visar tanto, por inúmeras razões, mas também devido à natureza da minha experiência, que é diferente por ser posterior ao momento em que as doutrinas de Romano penetraram no ensino do direito internacional, suscitando notáveis modificações. É pelo menos provável que uma parte significativa do pensamento de Santi Romano tenha sido absorvida por mim, e por muitos outros, sem a plena consciência da sua original matriz, porque já tinha se afirmado na escola italiana no momento das nossas primeiras experiências.

O meu encontro com as doutrinas de Santi Romano aconteceu justamente no primeiro "impacto" com o direito internacional, que em Padova, onde eu estava estudando direito, era matéria do segundo ano. As primeiras leituras me tinham colocado perante as construções do mais radical normativismo que procediam mediante dedução da Grundnorm "pacta sunt servanda". Tratando-se, entre outras, de doutrinas que se mantinham ancoradas na noção de que o direito advinha da vontade do Estado, o embaraço do jovem estudioso tornava-se insuperável: fora das audaciosas construções conceituais, qual era a resposta à questão elementar acerca da existência e da natureza deste direito internacional? Recorri a uma sugestão do meu primeiro, inesquecível professor, Donato Donati, que não hesitou em sugerir como texto o Corso di diritto internazionale de Romano, na edição de 1929 (a segunda), que desde então sempre tive à mão.

Tendo me transferido para Genova, lá me encontrei com o insigne estudioso dos fenômenos da vida jurídica internacional que foi o professor Pro-spero Fedozzi, de quem tive ocasião de me aproximar no último ano de sua vida e de ensino. $\mathrm{O}$ encontro com as doutrinas de Santi Romano se renovava, deste modo, no encontro com um internacionalista particularmente rico de dados e experiência, o qual tinha aderido aos conceitos de Romano e os tinha colocado como base da construção sistemática que elaborava, estendida por primeiro ao direito internacional público e depois ao direito internacional privado.

A minha posição a respeito do pensamento e das lições de Romano é, então, bem diferente daquela de quem, como Giorgio Balladore Pallieri, esteve entre os 
protagonistas do vivo debate de escolas e de tendências, na qual foi delineada e exercitada a influência de Romano.

Para mim, o pensamento de Romano foi o ponto de partida e a lição de base, e este é um fato que condiciona de modo inevitável a minha análise crítica.

\section{2}

A avaliação do contributo de Santi Romano ao direito internacional deve ser realizada sob dois prismas diferentes: considerando, em primeiro lugar, as concepções existentes no momento em que Romano desenvolveu a sua robusta ação crítica e reconstrutiva; e, em segundo lugar, valorando o quanto permanece desta ou também quanto desta pode ser re-proposto em relação às tendências posteriores. Em ambos os casos será motivo de reflexão o confronto das construções de Romano, ou que dele derivaram, com as realidades do seu tempo e com aquelas posteriores.

Pode-se afirmar que, entre as razões da ampla influência do pen-samento de Romano na Itália, é preeminente a solução que ele forneceu ao problema teórico do objeto do conhecimento jurídico. Para Romano, não é um sistema de normas, mas toda forma-ção social individual, já que toda sociedade contém o seu próprio direito - do qual é inseparável -, que se expressa nas suas mesmas estruturas ainda antes do que no aparato normativo com o qual a mesma sociedade venha dotada. Aparato válido dentro dos limites determinados pelas estruturas sociais, que constituem o fundamento e a medida da verdade e da efetividade das normas.

Como afirmamos, a compreensão do direito que deveria ser realizada pela sociologia não é uma conseqüência aceita por Romano, que, ao contrário, reivindica para a ciência jurídica a tarefa de conhecer inteiramente o fenômeno social, considerando-a apta para isto. De fato, muitas vezes ele afirma e reitera que entre sociedade e instituição, e entre instituição e ordenamento jurídico, existe uma mesma identidade: por conseqüência, também entre sociedade e ordenamento jurídico. Pareceria, então, que os motivos de discordância poderiam prevalecer sobre os que conduzem a adesão ao núcleo central da sua construção, sendo verdade o fato de que os primeiros foram salientados posteriormente, mas não inicialmente, e as razões disto são interessantes.

Em primeiro lugar, sua concepção tomou força persuasiva através da capacidade que tinha de oferecer uma resposta fácil à interrogação que atormenta desde sempre o jurista: como se verifica e por quais elementos seja atestado o "ser" do direito. Sendo a experiência jurídica entendida, segundo a tradição, como experiên- 
cia de fenômenos deontológicos, a positividade do direito, ou seja, a sua existência no âmbito dos fatos, tornava-se dificilmente demonstrável. Se o direito pertence ao mundo do "dever ser", parecia inevitável que ficasse fora da experiência empírica, relativa ao mundo do ser. Da contraposição então reconhecida como categórica entre o "ser" e o "dever ser" tinha-se como conseqüência a necessidade de construir todo o direito fora da experiência empírica. Neste sentido se desenvolvia toda a teoria normativista do direito e, com a maior coerência, através da "reine Rechtslehre" kelseniana. Esta concepção isola do "ser" o mundo do "dever ser", sendo que as dificuldades que levanta tanto para o jurista teórico quanto para o jurista prático estão na base da reviravolta feita por Santi Romano, que prefere negar e excluir a singularidade da experiência jurídica a respeito daquela naturalista do fato social. Deste modo, a posição anti-kelseniana de Romano é a primeira razão do sucesso que as suas concepções tiveram, como reação às dificuldades que o jurista encontra na construção normativista absoluta proposta por Kelsen.

A segunda razão para a ampla influência de Romano está ligada ao fato de as suas lições terem dado uma resposta ao problema capital do positivismo jurídico, ou seja, identificar o direito existente no mundo dos fatos através da identificação entre direito e sociedade. Esta parece ser a resposta mais coerente e completa aos postulados e às exigências que a corrente positivista fez valer, mas também parece ser a primeira que, no âmbito daquele corrente, consiga evitar o erro capital do positivismo, ou seja, aquele que consiste em pôr na base do direito a vontade do Estado. Erro sob todos os aspectos e devido às suas numerosas conseqüências: por introduzir na base de uma construção que queria ser rigorosamente científica, ou seja, baseada em dados fenomênicos, nada mais do que um dogma; por colocar o Estado fora do Direito e, deste modo, também o ramo do direito que seria expressão do Estado; por configurar o Direito como produto de uma vontade autoritária, o que retira todo o significado autônomo ao Direito, reduzindo-o a mero reflexo do poder e da força; por, enfim, de um lado negar a multiplicidade natural das formações sociais, capazes de expressar valores, linguagens e, do mesmo modo, ordenamentos próprios, mas, de outro, excluir todo e qualquer elemento que reconstrua qualquer tipo de unidade da vida social além da vida interna dos Estados individualmente, o que colocaria o Direito fora da experiência histórica concreta, sendo considerado expressão exclusiva, caso a caso, das vicissitudes dos Estados individualmente, arbitrariamente isolando-as.

O famoso livro de Santi Romano L'ordinamento giuridico desenvolve cada uma destas críticas através de uma análise coerente que se tornou possível graças à visão do direito como fenômeno social, compreendendo a sua força inovadora e sugestiva. Desta forma restitui-se ao jurista o objeto das suas investigações, libera- 
do dos dogmas e sem limites pré-concebidos sobre a natureza e a extensão das mesmas investigações.

\section{3}

Mas a obra de Santi Romano não se limita somente a isto, sendo que estaríamos diminuindo o seu valor se considerássemos dela somente a inspiração teórica fundamental. Mesmo se nos limitássemos à leitura do seu livro fundamental, L'ordinamento giuridico, não se poderia deixar de admirar a vastidão dos interesses culturais, os quais se expressam em uma riqueza de intuições e de observações, cada uma das quais encontrará amplo desenvolvimento na literatura posterior. A convicção expressa no livro, de que o jurista deve possuir uma experiência total do fenômeno social, longe de ser reduzida a uma enunciação teórica, se traduz na ilustração da complexidade articulada pelas formas jurídicas em que se expressa a ordem social, e na recuperação de experiências jurídicas longínquas no tempo e no espaço, fazendo com que a tese teórica venha valorizada pela possibilidade que esta revela de ampliar os horizontes do conhecimento de direito.

Um aspecto que talvez não seja bastante valorizado da obra de Ro-mano constitui-se pela inspiração historicista que a transpassa, determinante na crítica que o autor faz ao dogma da estatalidade do direito. É prova disso o apreço que tal obra encontrou na historiografia jurídica mais cautelosa e empenhada, como é evidente pelos estudos de Francesco Calasso, grande mestre da moderna historiografia jurídica italiana.

A inspiração historicista se revela muito influente justamente na visão que Romano apresenta do direito internacional público, toda sintetizada nas dez páginas do seu Ordinamento giu-ridico que se iniciam na página 44. Inspiração que também significa conhecimento e penetração em culturas jurídicas diferentes daquela então dominante na Itália, fazendo com que Romano se insira em primeiro plano entre os autores que abriram a estrada para a reflexão sobre conceitos jurídicos preeminentes da cultura anglo-saxã, procurando e encontrando os respectivos elementos para as concepções estatal-positivistas que se afirmaram (mas também estas por razões históricas bem precisas) sobretudo na Alemanha e na Itália. Aqui deveríamos deixar espaço às citações, mas seriam de tal amplitude que acabam por justificar uma sugestão muito mais racional: retornemos a uma atenta releitura do seu livro fundamental e dos outros por ele publicados; serão inumeráveis as surpresas e não deixaremos de encontrar, algumas vezes em breves menções, teses e noções posteriormente desenvolvidas, de modo amplo, por autores que algumas vezes nem mesmo conseguiam recordar as longínquas leituras de onde tinham ger- 
minado as idéias de Romano, e que posteriormente se desenvolveram em construções mais amplas. De certo modo se poderia dizer que, em muitos, cometemos erros em relação a este nosso jurista, entre os maiores do nosso tempo, sendo que ele deixa transparecer um certo pesar a respeito, um pesar que nos atinge, sempre do seu modo elegante e comedido, em alguma das notas inseridas na reedição do L'ordinamento giuridico, enviada ao prelo em novembro de 1945.

Permitam-me ainda uma anotação: o quanto seja feliz e rica a expressão literária deste nosso jurista, fazendo com que nem pareça que se passou mais de meio século - e que século! -, ao hoje reler as suas páginas. A leitura é fácil e agradável, a escrita é simples e plana, nada ou quase aparece hoje vetusto ou estranho: certamente Romano tinha como finalidade, e a atingiu, ilustrar os temas fundamentais de estudo jurídico elevando-se ao plano da cultura geral, à qual o direito pertence, já que não se reduz ao campo, nem pode se valer do linguajar de interesses especializados, mas diz respeito a toda vida do homem; e esta é uma outra, certamente não secundária, das suas lições. Uma elaboração que não poderia deixar de se traduzir no equilíbrio de valorizações e de apreçamentos que evitam a tentação das contraposições polêmicas, mas conduziram, ao contrário, a um adequado apreçamento também das doutrinas que ele rejeitou.

\section{4}

No que diz respeito, em particular, ao direito internacional a contribuição de Santi Romano deve ser considerada notável sob múltiplos aspectos, os quais nos limitaremos somente a recordar, seja porque estão entre os mais conhecidos, seja porque o próprio Romano colocou em primeiro plano o direito internacional, fazendo-o "pedra de paralelo" para a sua definição de direito. De fato, ele inicia a análise de tal ramo do direito na página 44 de L'ordinamento giuridico, escrevendo: "Para toda definição do direito, a pedra de paralelo é determinada de um modo especial pelo que se afirma ser o 'problema do direito internacional', e conseqüentemente não será inútil que analisemos este tema. De fato, não nutrimos dúvidas quando consideramos errôneas ou incompletas as definições que chegam a negar o direito internacional, seja na sua existência, seja - o que não é muito diferente - na sua autonomia, enquanto o consideram como uma externalização ou projeção do direito interno dos vários países. A definição de direito deve ser dada fazendo com que nesta possa ser compreendida não somente o que por tradição científica, mas também por sentimento comum e sobretudo por uma prática constante nunca desmentida, assim é considerado. Se não fosse assim, tal definição seria arbitrária: o jurista não deve subordinar a realidade ao conceito, mas sim o conceito à realidade”. 
Da elaboração fornecida por Romano para a matéria bastará relembrar alguns pontos salientes. Em primeiro lugar o fato de negar que tenha razão de ser aquele problema, ligado ao fundamento do direito internacional, que no período vivido pelo autor constituía o capítulo inicial de grande parte das análises. Corretamente, Romano se opõe afirmando que o único problema pode ser o de verificar ou não a existência e as características de um ordenamento que corresponda a uma sociedade internacional entre Estados. E de um modo também aguçado ele identifica os pressupostos que obrigam a doutrina positivista a se colocar aquele problema, ou seja, em primeiro lugar a aceitação do dogma da estatalidade do direito; em segundo lugar, a troca das características próprias do direito estatal pelas características gerais do direito; em terceiro lugar, uma insuficiente amplitude no enquadramento histórico da matéria; e, enfim, o erro, que é um erro lógico antes mesmo que histórico, de configurar o direito internacional como um produto da coexistência de Estados independentes, e não como a expressão direta e imediata daquela coexistência.

Não importa se o tipo de raciocínio que ele conduz sobre um ou outro destes pontos fundamentais seja algumas vezes datado, refletindo debates de doutrina que naquele período eram atuais, e nem poderia -ser diferente. Na realidade cada um daqueles pontos será posteriormente sempre mais salientado nos estudos internacionais, demonstrando a profundidade das intuições e a penetração crítica do pensamento de Romano.

Entre as partes da matéria em que Romano possui o mérito de ter proposto soluções diferentes daquelas então dominantes devem ser recordadas ao menos as que seguem. Em primeiro lugar a teo-ria das fontes, naquele tempo dominada pela concepção de que o tratado seria a fonte de onde emanaria o direito internacional, resumindo-se, mesmo o costume, em um tratado tácito. Santi Romano se opõe àquela concepção afirmando, por um lado, a existência de princípios fundamentais inerentes à estrutura da instituição constituída pela sociedade dos Estados, por outro lado, a irredutibilidade do costume a um acordo tácito, baseado na distinção e autonomia do mesmo, já que a amplitude da sua dimensão normativa - que todavia ele exclui seja preeminente a respeito do tratado. Por isso, considera ambas as fontes expressões imediatas e igualmente originárias do ordenamento.

Em segundo lugar, no que concerne à composição da sociedade internacional e aos seus sujeitos, ele não deixa de salientar que nem sempre e nem necessariamente todos os Estados fazem parte dela, considerando que a mesma instituição é, ao contrário, constituída pelos Estados que, nos diferentes tempos, vierem a fazer parte.

Em terceiro lugar, no que diz respeito ao argumento no mínimo controvertido das sanções, considerado por muitos como o ponto crítico do problema da juridicidade 
da sociedade internacional, ele enuncia a tese que é essencial em um ordenamento jurídico, ou seja, a da adequação das garantias de eficácia que neste estão contidas, e não, ao contrário, a predisposição de sanções seguramente atuantes em relações às violações do direito.

Não mencionaremos a tese romaniana de que o ordenamento internacional seja munido de uma constituição bem definida, que está entre as suas contribuições ao desenvolvimento teórico de direito internacio-nal, por duas razões: por um lado, porque se trata de uma mera dedução que ele extrai da definição de direito como estrutura social, ou instituição, sem que a afirmação venha a ser justificada pela identificação das normas que regulariam a ordem constitucional da sociedade internacional, e, por outro lado, porque aquele conceito de constituição, como mero reflexo ou cópia de uma estrutura social algumas vezes mais pressuposta do que demonstrada, é um dos pontos que não poderiam deixar de ser criticados, como o faremos a seguir.

\section{5}

Seria um erro inadmissível avaliar hoje a obra de Romano e a sua contribuição ao direito internacional não levando em conta a sua inserção histórica: todas as considerações precedentes tiveram de levar em conta tal exigência fundamental. Ora, se refletimos a situação de profunda crise por qual passava o direito internacional - da qual a primeira guerra, então em curso, era o desemboco e não somente a manifestação - nos motivos já mencionados, o apreçamento pela posição assumida por Santi Romano somente aumentaria. Isso devido a sua postura de convicto apoio às perspectivas de reafirmação e de recuperação dos valores jurídicos nas relações entre os Estados. Uma postura que será confirmada e reiterada no Corso - evitando exageros irreais e por conseqüência mistificadores dos dados de fato fazendo com que não possa ser esquecida a vocação também ideologicamente internacionalista do autor em um período histórico caracterizado, e certamente não só na Itália, por uma vigorosa tendência contrária ao internacionalismo, rejeitada por estudiosos e por movimentos políticos de oposição, mas certamente não pelos governos e nem pela diplomacia.

A idéia fundamental de Romano de que a comunidade internacional é por si mesma uma instituição, ou seja, uma sociedade distinta de qualquer outra e que corresponde à coexistência dos Estados, contém por si mesma a negação das concepções nacionalistas do direito internacional (não necessariamente coincidentes com ideologias nacionalistas), que tendem a reduzir o direito internacional a somente pactuações com as quais os Estados se obrigam entre eles, exercitando sua sobe- 
rania, entendida como origem e fundamento de todo o direito, permanecendo árbitros de seu próprio comportamento.

Da premissa romaniana de que todo Estado é uma instituição, ou seja, um ordenamento jurídico, e de que também a sociedade por estes constituída assim o é, advém toda uma série de perspectivas e de possibilidades relativas às relações entre estes ordenamentos, compreendido o internacional. Tal fenômeno oferece esquemas muito mais articulados e, portanto, mais adequados ao enquadramento de uma realidade que não é somente poliforme, mas também bastante mutável.

Ainda resta um ponto a ser salientado: a concepção institucionalista de direito traz consigo inevitavelmente a tendência a explorar os elementos institucionais presentes em um ordenamento. Se tal tendência pode algumas vezes conduzir ao erro de considerar como instituições jurídicas em sentido próprio, ou seja, como aparelhos juridicamente organizados e disciplinados, estruturas sociais que não são objeto de regulação jurídica, todavia, a mesma tendência se revela iluminadora e metodologicamente preciosa quando se trata de indagar sobre o conteúdo e as características de sistemas jurídicos como o internacional, em que os elementos institucionais são escassos e algumas vezes ausentes. De fato, segundo um ponto de vista que consideramos fundamentado, a disciplina jurídica das estruturas sociais chega algumas vezes a se afirmar no direito internacional, mas em outros períodos isso não acontece, fazendo com que o direito internacional sofra limitações, reduzido, em tal caso, a um sistema de regras de comportamento definível como direito comum. Encontra-se em contraposição a tal aspecto de direito internacional a idéia da sua periódica integração com instituições, ou seja, com um direito institucional.

Mesmo não concordando neste ponto com Santi Romano, devido ao fato dele conceber o direito internacional como ordenamento sempre munido de instituições - sendo este mesmo uma instituição -, deve-se reconhecer a contribuição dada por sua concepção institucionalista para a identificação dos dados institucionais presentes, quando o sejam, no direito internacional. Isto que, sobretudo olhando para a época em que se desenvolveu o trabalho do Romano, não poderia ser deixado de lado, nem poderia ser negado o apoio teórico e doutrinal, que dele advém, para a afirmação progressiva de uma organização da sociedade internacional mediante instituições propositalmente criadas.

\section{6}

É interessante examinar as razões que têm mantido viva, contra o enquadramento dado por Romano ao direito in-ternacional, a concepção normativista que se opõe a ele, prevalente nas lições e na doutrina até o momento em que se 
delinearam, após a Segunda Guerra Mundial, concepções novas, diferentes de ambas e que advêm, entre outros, até mesmo de uma assimilação conjunta delas.

Existem razões de teoria geral, mas estas serão mencionadas mais tarde. Interessam agora as razões que dependem das características jurídicas da sociedade internacional (entendida, segundo a tradição, como sociedade constituída e advinda da coexistência dos Estados), assim como identificadas por especialistas e grandes mestres, tais como Dionisio Anzilotti e Tomaso Perassi, e que sugerem um enquadramento oposto a respeito daquele sugerido por Santi Romano, ou seja, sem elementos institucionais. A sociedade internacional se demonstra, para as tendências às quais nos referimos, que certamente são as mais influentes, como privada de características institucionais no sentido mais restrito que antes mencionamos, e sem uma constituição entendida como disciplina normativa das suas estruturas orgânicas; por isso seria construível em termos jurídicos tendo por base somente uma noção que exclua a necessária identidade entre direito e instituição, e que conceba o direito como um sistema de normas sem que o mesmo sistema deva necessariamente estar integrado pela regulação jurídica das estruturas sociais que constituem um pressuposto de fato, não o objeto.

Tal visão da sociedade internacional dos Estados foi recentemente definida através da noção e da expressão, enunciada há pouco, de direito comum, que se contrapõe àquela do direito institucional. Deve ser considerado verdade o fato de a sociedade internacional ter sido privada de instituições, sendo deste mesmo modo privada de uma constituição no sentido jurídico na maior parte da sua evolução histórica moderna, e que era particularmente carente de normas que regessem as suas estruturas fundamentais durante a grande crise que a dominou desde o princípio do século XX até a criação das Nações Unidas. Daí parece ser uma representação adequada da realidade existente no âmbito dos fenômenos jurídicos a representação oferecida pelas escolas substancialmente prevalentes, baseada em um puro normativismo, ou seja, concretamente excluindo normas de organização e construindo o sistema como puro e simples direito comum.

Deste modo, então, pode-se compreender como se preferiu o esquema normativista puro tradicional - mais do que o conceito institucionalista de Romano para ser instrumento de cognição e de representação de um sistema normativo em que são constatáveis normas reguladoras e avaliadoras do comportamento dos sócios, mas não são encontráveis, ao contrário, normas de organização das estruturas sociais, as normas constitucionais. A exclusão destas últimas devido à constatação ou convicção de que de algum modo a ordem social não é determinada por normas jurídicas deveria trazer consigo a exclusão daquele conceito institucional do direito que se coloca como elemento essencial para a constituição: o elemento que transforma o fato natural de uma estrutura social na sua projeção jurídica constituída por normas de organização. 
Complementando o que foi dito, deveria ser acrescentado, do ponto de vista de Romano, que o sistema normativo advindo da representação que lhe foi dada nos termos acima citados não seria direito, não constituindo um ordenamento jurídico. Mas, na realidade, Romano não discorda no que concerne à constatação dos dados e nem, portanto, do fato de não se poder extrair do direito internacional da sua época uma disciplina da competência e de exercício das posições de poder. Ele considera, ao contrário, que a ordem social, qual seja esta, é por si mesma organização jurídica, ou seja, constituição. Ponto sobre o qual se concentra a discordância com a escola que a ele se contrapõe ao negar a juridicidade a tudo aquilo que não se encontra previsto em normas jurídicas.

\section{7}

O contraste entre as doutrinas mencionadas revela os limites teóricos e metodológicos não somente da concepção de Romano, mas também da concepção normativista que a ele se opõe. Meio século de evolução do pensamento jurídico e de transformação das realidades sociais justifica uma revisão crítica que nada tira ao apreço da contribuição dada por aquelas concepções e por outras do período, seja na superação do positivismo estatalista, seja na identificação de novos problemas e perspectivas para a ciência jurídica.

A concepção de Romano tem a virtude de ter feito valer a exigência de uma investigação indutiva no campo jurídico, mesmo se deixou de referi-la aos dados de uma experiência mais propriamente jurídica. Experiência que significa constatação de fenômenos caracterizáveis como jurídicos no âmbito bem mais amplo de todos os fenômenos sociais. As concepções normativistas que a ele se opõe têm a virtude de se referir à singularidade de uma experiência irredutível a esquemas naturalistas. Todavia, elas não atingiram a consciência da factualidade do elemento normativo, se negando, deste modo, à investigação indutiva e se obrigando a buscar em outras ordens de conhecimento (escassamente disponíveis a fornecer os elementos por estes solicitados) todas as premissas sobre a qual se ergueu a construção jurídica, para fazê-lo com método essencialmente, se não exclusivamente, dedutivo.

Se em relação a tais concepções o indutivismo de Romano pode vir a ser motivo de crítica, em relação também a esta, como às outras, deve ser objetado que a referência ao fenômeno social se torna, na realidade, uma referência cômoda se não se traduz em uma persuasiva determinação das respectivas tarefas da investigação jurídica e da investigação sociológica. Neste ponto, Romano tem razão quando rejeita as críticas de sociologismo, por ser verdade que a sua construção - até mesmo a sua teoria - é eminentemente jurídica, ou melhor, jurisprudencial. Mas 
esta característica contradiz as suas enunciações teóricas. Os normativistas, por eles, pressupõem uma determinação sociológica dos dados de base sobre o qual o sistema se constrói, mas tal pressuposição fica por um lado sem objeto, por não ser regida por investigações coerentes e, por outro lado, faz com que falte à investigação sociológica a contribuição que compete aos juristas, ou seja, a identificação dos fenômenos intrinsecamente jurídicos com a elaboração e a construção dos mesmos.

Se é verdade o que se afirma, deve-se reconhecer que tanto uma quanto as outras doutrinas e escolas compartilham uma dupla insuficiência. Possuem, em primeiro lugar, falhas no que concerne à seleção e à constatação dos dados fenomênicos intrinsecamente jurídicos, por serem estes fragmentados e confusos com outros dados fenomênicos ou por estar fora do âmbito da investigação jurídica. Em segundo lugar por reconhecerem, todas, a necessidade de uma referência aos fenômenos sociais (diferentes dos jurídicos) e de um confronto com fenômenos jurídicos, mas por se limitarem à pura afirmação, excluindo a possibilidade de verificação sociológica do conteúdo e da incidência real das construções jurídicas propostas.

As insuficiências aqui mencionadas acabam por conduzir, mesmo na diversidade das premissas e das intenções, a uma concepção totalizante de conhecimento jurídico, que é explicitamente professada por Romano, enquanto não o é nas tendências opostas, sem, contudo, que o resultado seja diferente. A ciência jurídica aparece, de todo modo, fechada em si mesma e utilizada como instrumento adequado, sozinha e por si só, a fornecer o completo conhecimento das partes da realidade social e das respectivas experiências que constituem o direito.

Uma outra conotação comum a todas estas doutrinas é a significativa expressão do delineamento examinado, ou seja, a noção totalmente e exclusivamente objetivista do direito, que as conduz a definir a tarefa da ciência jurídica como a cognição de um sistema existente na sua objetividade e completude, fora e, então, antes mesmo da sua cognição, como uma realidade a respeito a qual a ciência não tem tarefas de elaboração crítica nem de construção sistemática, mas de pura descrição do exterior, fazendo com seja reduzida à mera interpretação jurídica. Certamente, a noção de ordenamento jurídico é aquela que expressa melhor tal visão do direito e dos limites da sua cognição.

Não se exclui a possibilidade de que o conhecimento do direito também deva afrontar a tarefa de se pôr perante seu objeto considerando-o como um elemento que existe fora da sua elaboração crítica e sistemática. Em tal caso, este conhecimento se transfere ao campo da investigação sociológica, devendo se valer de instrumentos de investigação apropriados que pouco têm a ver com a interpretação jurídica ou com a construção sistemática, as quais deveriam, na verdade, tê-lo já 
absolvido a sua insubstituível tarefa. Sem este nos faltaria o objeto que se quer conhecer como tal e sob outros aspectos.

Deve ser reconhecido a Romano, ainda uma vez, o mérito de ter tido uma intuição antecipadora. A sua tese, baseada em uma ilimitada pluralidade dos ordenamentos jurídicos, constitui o reconhecimento da natureza pluralista de todas as sociedades e da natureza conflitual das relações sociais. Ademais, esta tese poderia significar que as forças sociais se tornam relevantes quando assumem elevadas características estruturais, permitindo que se configurem como sociedade e, por isso, como ordenamentos jurídicos.

Consideramos, todavia, que a segura validade da intuição romaniana seja deturpada quando é construída. Isso pode somente criar perplexidades devido ao fato de que aquela intuição, que se expressa no reconhecimento da dinâmica existente em qualquer agregação social (que traz consigo a dinâmica do fenômeno jurídico, ou seja, a sua irredutibilidade a um sistema fechado), vem posteriormente comprimida pela noção de necessária unidade e coerência do ordenamento, fazendo com que a conflitualidade seja lançada para fora de cada ordenamento, como matéria das suas relações.

Devemos complementar, neste ponto, evitando mal-entendidos, que a negação da unidade e da coerência do direito pode somente se referir ao elemento fenomênico, onde a mesma conflitualidade e os elementos de contradição de fato existentes devem encontrar um enquadramento racional na construção sistemática. Isso significa que tal construção deve ter e dar conta delas, evitando transferir para dados fenomênicos as próprias exigências de coerência e de harmonia lógica.

A construção sistemática não pode ser reduzível a termos puramente fenomênicos, já que é o produto ou a expressão de um contexto político-cultural que transcende o dado de fato.

Para concluir, os principais motivos de discordância hoje identificáveis em relação às teorias de Santi Romano dizem respeito mais ao objetivismo que se afirmou como dominante na ciência jurídica e que só recentemente foi colocado em discussão pelas progredientes tendências críticas. Estas estão conduzindo a uma revisão das doutrinas, que revela a falta de fundamentos gnoseológicos das mesmas, de onde advêm as prevalentes incertezas metodológicas.

A doutrina que prevalece realiza a sua análise através de contraposições dualistas quase sempre injustificadas e desviantes, como é aquela entre "ser" e "dever ser". Contudo, atualmente tem despertado maior interesse a contraposição dualista entre o "ser" do direito e o conhecimento do direito, devido, evidentemente, as definições pré-concebidas e mitificadoras do direito. Devido ao fato de o aspecto teórico das lições de Romano acentuar o citado objetivismo através da sua noção de 
base - a de ordenamento jurídico entendido como instituição social -, é justamente aquela- noção que acaba por ser mais atingida pelas tendências críticas, justamente onde se deveria, ao contrário, reconhecer que os seus interesses científicos e os problemas por ele afrontados são freqüentemente uma antecipação muito mais articulada e complexa de uma visão do direito e das tarefas do jurista.

Ainda uma vez nos encontramos a reconhecer que a crítica a Santi Romano não deve ser apressada porque, mesmo encontrando fundamento em alguma das suas teses, pode acabar por ser posteriormente desmentida devido à vastidão dos elementos por ele analisados e pela variedade de aspectos que utiliza para a sua valoração.

Encontra-se um exemplo imediato disto no confronto entre a segunda e a primeira parte do seu livro fundamental, sendo que as críticas de inadequação freqüentemente formuladas poderiam ser dirigidas somente à primeira parte. Esta primeira parte dedica-se sobretudo à enunciação das teses teóricas, enquanto a segunda parte é mais voltada à construção de uma teoria geral dos sistemas jurídicos. Se toda releitura da obra (e das outras, e dos cursos) é sempre um prazer e uma redescoberta, a releitura da segunda parte do seu Ordinamento giuridico ainda é uma introdução válida ao estudo do direito, nas suas novas configurações e nos seus mais recentes aspectos, o que vale também para o direito internacional. 